\title{
Master's program "ballet and synthesis of plastic arts" in the context of world integration interactions and the main aspects of its study
}

\begin{abstract}
The article considers the structure of the author's program and the main directions of its development in the system of interaction between culture and education in the context of world integration interactions. Its conceptual idea and content are focused on real scientific and methodological cooperation of related spheres of knowledge, which should lead to a qualitative improvement of the educational process based on programs of an integrative nature. Favorites for the basis of the art of ballet theater with access to the forefront of plastic arts opens wide opportunities for the development of academic research on the general background of the artistic culture of the world.
\end{abstract}

Keywords: master's program, ballet, synthesis of plastic arts, sphere and methodology of research, practical significance
Volume I Issue 3 - 2017

\section{Tatiana Vasilievna Portnova}

The departments of art Choreographer, Russian State

University named after AN Kosygina, Russia

Correspondence: Tatiana Vasilievna Portnova, The departments of art history, Russian State University of AN Kosygina, Russia, Email infotatiana-p@mail.ru

Received: July 29, 2017 | Published: November 29, 2017

\section{Introduction}

The program is formed on the basis of author's scientific, educational-methodical, project development of an interdisciplinary nature: ${ }^{1}$ Spiritual demands of modern society require a high level of comprehension of reality, correlated with the common tasks of the culture of the 21 st century. Interaction and interpenetration of sciences became an indispensable condition for their further development. Today it is difficult to find a major problem of one science, which would not attract the attention of a whole complex of others. The tendency to their synthesis is unquestionable in the development of modern theatrical art, the tendency to diffusion of expressive means dominates, which occurs at the boundaries of its individual species. Sometimes the performance looks like a mosaic gathered from various elements, which naturally raises the question of its specific boundaries, the preservation of the specifics of the means of expressiveness, and even the independent existence of theaters within the framework of the system that has historically evolved to the present day. ${ }^{2}$ We observe this and in the emergence and development of new types of artistic creativity, which is caused by the urgent need for life to create a single and integral scientific and cultural picture of the world that corresponds to the present level of accumulated nnyh knowledge. This requires improving the professional skills of filmmakers, screenwriters, cameramen, directors, artists, actors, art theorists, awakening the spirit of innovative ideas; bold search new themes and expressive possibilities of the language of the ballet theater. These tasks arise not only for ballet studies in a narrow sense, but also for the pedagogy of art and synthetic art history, should be reflected in the curriculum of a master's level focused on a systematic and systematic study of not only history but also contemporary theoretical and practical problems of the theatrical arts. "The nature of the ballet genre involves the unification of many arts: plastics, music, painting (decorative art), and in a number of phenomena (especially at an early stage of genre development) - singing and recitation". 3

\section{Relevance}

Analysis of the scientific literature allows us to conclude that the traditionally problematic field of research of the ballet is associated with the art criticism of knowledge, which, in our opinion, significantly narrows the range of raised issues of comprehension of classical ballet art. The existing practice marked the beginning of studying traditional theatrical disciplines in theatrical and creative educational institutions: "The History of Ballet", "The Art of the Choreographer", "The Choreographic Work", "The Choreographic Direction", "The Composition of Classical Dance", etc. ${ }^{4}$ However, courses based on innovative technologies for designing complex systems, using visual materials and other visual sources, attracting computer technologies and programs are called upon to play an invaluable role in the learning process. In the new cultural context, the problem of enriching the choreographic language and gradually ousting the repertory theater and its traditional essence with a high-tech theater of stage design is acute. Modern theatrical criticism in the evaluation of scenic works increasingly relies on a number of fundamental and applied disciplines: art criticism, literary criticism, cultural studies, philosophy, structuralistics, linguistics, source study, including theater design, computer technologies and polychological tools.

\section{Goal and tasks}

The main goal of the master's program is to prepare specialists for the creative profile to professional scientific, educational, project, intellectual-capacious activities by studying the field of scientific research, mastering the skills of conducting interdisciplinary research and projects, mastering innovative intellectual technologies for generation, processing, presentation of knowledge. The main tasks: to deepen, expand and improve the basic professional knowledge and skills of the listeners, to form the skills of the system approach, motivational attitudes towards self-management of scientific research activity, improvement and development of its own intellectual, general cultural and scientific potential, its application in the subject field of professional activity.

Achieving this goal is accomplished by solving the following tasks:

a. To reveal philosophical and methodological paradigms of interdisciplinary research of ballet and plastic arts and on this basis to comprehend cultural civilization as an integral, self- 
developing phenomenon of scientific, creative and sociocultural transformations;

b. To reveal the peculiarities of the formation and development of synthetic forms of ballet from the standpoint of the interdisciplinary approach of master's studies;

c. To determine from the standpoint of the interdisciplinary approach the specifics of the development of cultural processes in the world, their civilizational status, as well as possible scenarios for the further development of the system of plastic arts.

\section{The target audience}

Graduates of the Bachelor's Degree of the Choreography, Art Criticism and other related creative areas, applicants and participants in scientific and creative projects.

\section{Competencies}

The study of the program contributes to the formation of the following competencies;

a. The ability to organize and conduct scientific research using knowledge of fundamental and applied disciplines mastered in the Master's program;

b. Knowledge of modern methodological principles and methodical methods of research on history, the theory of synthesis of arts;

c. The ability to analyze and generalize the results of scientific research on the basis of modern interdisciplinary approaches;

d. Mastering the preparation and conduct of scientific seminars, conferences, preparation for editing scientific publications;

e. The ability to analyze and explain historical, cultural, historical, artistic, sociocultural, semantic, iconological, iconographic, formal-figurative and formal stylistic factors in the development of synthetic art in the context of the ballet theater;

f. Have the skills to apply modern information and communication technologies in the learning process;

g. The ability to formulate and solve tasks related to the implementation of organizational and managerial functions, the ability to use the methods of the sciences studied for their implementation;

h. Mastering the skills of preparing analytical information (taking into account the historical, cultural, historical, artistic, historical, ethnographic, artistic and art context) on the theme of the dissertation research;

i. The ability to use historical and cultural, historical and artistic, historical and ethnographic, art criticism in the activities of organizations and institutions (archives, theater museums, art galleries, art and historical and cultural funds, etc.)

The graduate must have the following professional competences (general competence for all types of activities):

a. The ability to consciously understand that choreographic art, through whatever disciplines it is studied, is interrelated, interacts and correlates with music, drama theater, visual arts, cinematography, humanitarian, social, physical and natural sciences; b. The ability to understand the relationship between theory and practice in various areas of choreographic art and to demonstrate their interrelationship by using various techniques and methods of realizing the acquired knowledge in practice;

c. The ability to demonstrate an in-depth understanding of the place of choreography in the evolution of mankind, the connections of dance with the social and cultural life of society, its role in the creation of artistic values; about the basic tendencies in development of world choreographic art and about features of this process in modern conditions;

d. The ability to demonstrate knowledge and experience in a wide range of practical, teaching, entrepreneurial and creative activities, including: the ability to negotiate, create their own image, conduct financial affairs, implement long-term planning, make presentations and reports, use a personal computer and communication facilities and To position oneself in the market of creative work;

e. The ability to navigate in the specialized literature on the field of activity, in related areas of artistic creativity, the ability to carry out an in-depth analysis of artistic works of various arts and eras;

f. The ability to collect, process, analyze, synthesize and interpret information from various sources, both in the field of activity and in related areas of artistic creativity, to form conscious and qualified judgments on appropriate creative, social, scientific and ethical issues;

g. Ability to dynamic activity: to work with diverse intellectual and practical tasks with high speed and accuracy, flexibly switching from one task to another;

h. The ability to realize in their professional activities valuesemantic principles: spirituality, multiculturalism, humanistic perception of the world, adequate social self-identification, innovation, creativity, meaningful updating of knowledge;

i. The ability to understand, consolidate and develop interpersonal relations, transfer and exchange of knowledge, thoughts, experiences, cultural and moral values and results of activities embodied in the material and spiritual culture in accordance with social norms and conditions for carrying out activities.

As a result of mastering the discipline "Analysis of choreographic works" the master must:

\section{Know}

a. Theoretical, methodological, methodological and organizational aspects of the implementation of scientific research activities in choreography.

b. A system for describing literary sources;

\section{Citation rules}

a. Rules for registration of research works;

b. Stages of work and communication with the supervisor;

c. Criteria for evaluating scientific research

\section{Be able to}

a. To reveal the program-target field of research, features of its organization; 
b. Reveal the essence of the methods of collection, processing and analysis of scientific research data;

c. To determine the perspective directions of scientific research in the subject sphere of professional choreographic activity, the composition of research works that determine their factors;

d. Use experimental and theoretical methods of research in the subject field of professional creative and pedagogical activity;

e. To adapt modern achievements of science and science-intensive technologies to the educational and self-educational process.

\section{Own}

a. Modern methods of scientific research in the subject field;

b. Ways of comprehension and critical analysis of scientific information;

c. Skills in analytical work with literature and databases;

d. The methodology for preparing statements, drawing up plans, theses, writing scientific articles.

\section{Scientific field and study vectors}

The scientific field of the study of the program "Ballet and the synthesis of plastic arts" presupposes a broad study of current topics related to the morphology of the ballet as a synthetic art form, various aspects of the interaction of stage dance and plastic arts (graphics, painting, sculpture, arts and crafts, architecture and other kinds creativity) to the study of a qualitatively new artistic phenomenon, not reducible only to the sum of the components, integral components. The paradigm of modern education assumes the active role of all participants in the educational process in the formation of a motivated competent personality capable of: quickly navigating in a dynamically developing and renewing information space; receive, use and create a variety of information; make informed decisions and solve life problems on the basis of acquired knowledge, skills and habits. The author of the program believes that today its material is extremely in demand in conditions of realization of not only national, but also world educational initiative.

The scope of master's studies can include little developed modern problems of the theory and history of the ballet theater, relating to classical choreography in the context of the organization of the stage space and the spatial arts interacting with it. These are the ideas of direction and movement in space, the questions of architectonics and the plastic form of ballet performance, the criteria for portrayal in dance, the principles of interaction of expressive and visual means, the problems of retrospective and innovative stylistic directions in ballet, the methods of reconstructing the choreographic heritage, the questions of the addition of academic schools of classical dance and the overcoming their boundaries from tradition to the pioneering quest for a dance in the open environment, museum and other spaces.

Another aspect of scientific master's searches may be topics related to the composition of museum and private collections, mainly theatrical profile, storing the graphic materials of ballet iconography and decoration. Thus, all platforms of the ballet theater with a complex of research problems that somehow come into contact with the existing structure of the visual artistic image in the work of artists and choreographers, as well as the forecasting of future new forms of visual visualization in the process of creating choreographic works, turn out to be involved here.
The dominant author's discipline included in the basic part of the master's training in the direction 071200 (52.04.01) "Choreographic art"-"Methodology of scientific research in choreography" Parallel courses that complement this discipline, creating a thematic specialized unit are: "Modern problems of science and art "," Analysis of choreographic works "," Synthesis of spatial and plastic arts "," Costume and scenic decoration of dance ", Ballet iconography "," Scenography of the ballet spectrum , "Philosophy of dance", "Author's concept, form, genre, vocabulary of the choreographic work", "Art criticism, historical, culturological, psychological and pedagogical approaches in research and critical analysis of works of choreographic art". ${ }^{5}$ Discipline "Methodology of scientific research in choreography" is fundamental for the study of all subsequent courses, since the knowledge and skills formed within its framework are methodological in nature and allow applying them in the field of modern technologies and methods for creating original creative projects and solving professional problems. ${ }^{6}$

\section{Methodology of development}

The method of mastering the master's program includes lecturing, conducting practical classes, interactive forms of research work (presentations, trainings, excursions, internships) during the first year of training. The lectures are provided on topics of theoretical importance. ${ }^{7}$ What are you doing? regions of finding the monuments of ballet iconography, involved in the concept of the program, will broaden and enrich the notion of the geography of the location, will encourage them to study. Participation in the programs of theater and art education, competitions, festivals and other events contribute to the popularization of art in society. Practical studies are devoted to problematic issues and are called upon to form the analysis skills of the synthetic work of ballet art, drawing up programs for its structural study. Practical classes are designed to build the skills of using knowledge about the features and specifics of various forms and genres of art, as well as the skills of directing a theatrical performance in future professional and cultural activities.

The course provides for the development of several scientific publications, educational and methodological developments, computer presentation projects, writing reviews for a ballet performance, organizing and conducting its own integrative mini research into the historical development of the ballet theater in one of the countries proposed, an analysis of the choreographic work of a certain genre, and it is possible to direct the visual decision of your own number or performance in the context of a spatial and plastic dialogue Sgiach arts. "should also be pointed to the fact that it was in the Russian socio-cultural space that the classical ballet was the subject of close attention, both to the audience and the subjects of state cultural policy, from the end of the 19th century to the last quarter of the 20th century. Stably maintaining the status of national pride. Geography of modern classical ballet is unusually wide - it includes all continents and most developed countries of the world. ${ }^{8}$ The interdisciplinary character of the research themes allows us to attract a wide range of concepts that encompass not only formal and methodological but also substantive aspects of ballet art. ${ }^{9}$ The knowledge obtained in the process of learning the program will be used in the course of scientific research. Inclusion of undergraduates, as a rule, a choreographic profile, in polirovolevy interaction with each other in presentations and reports at the consultations of the research cycle significantly activates the adaptive processes aimed at further professional activity. ${ }^{10}$ The main provisions of the prepared master's theses and conclusions obtained will not only significantly expand the already available information on the problem 
under study, but also develop a new methodology for examining the phenomenon of choreographic art from interdisciplinary positions.

\section{Practical significance}

The competences of the master's program are aimed at the ability of graduates to introduce innovative technologies that take into account the needs of society, to design activities in the field of culture and art (projects of museums of theaters, art exhibitions and ballet exhibitions, houses of culture and creativity), to the protection and reconstruction of cultural values. They are also oriented towards the readiness to develop the goals and priorities of the scientific and creative activity of scientific research, educational institutions and cultural institutions that realize the pedagogical, directorial, artistic-staging and actorperforming types of professional work of the choreographer and artist. The practical orientation of the developed program includes the use of different approaches (functional-realistic, artistic-creative, sociallyoriented and others), the correlation of scientific disciplines and their methods in complex art research. Strategies for specific integrated research and approaches contain a "Context-concept-project", exist as stages of integrative design. Today, in conditions of dynamic changes in society, design becomes an algorithm not only of design and architecture, but also a form of social practice, and the synthesis of plastic arts must include not only the principles of space organization, but also social models for the further development, preservation and improvement of aesthetics and beauty in human life.

\section{Conclusion}

The final importance of the master's program consists in mastering the skills of collecting and processing information, the methodology for conducting scientific research in the field of ballet and related plastic arts, with the basic rules for the use of professional vocabulary; conceptual - categorial apparatus of the art of integrative science, professional culture of the presentation of the material and the skills of using sources and scientific literature in the process of creating the scientific text of the master's thesis. ${ }^{11}$ The priority of project education is now recognized by the entire world community, as it presents the social creativity of students in various organizational forms of activities to create new material and spiritual values in the interests of the society. The process of activity during the two years of training is improved under the influence of its own product - the project and each new level of education involves the resumption of the cycles of the functioning of design on the basis of the synthesis of plastic arts with the complication of the program sections. The methodology of the theatrical project activity reveals its dialectical character, the complex dynamics of cognitive, creative and research activity in the context of the relationship between the head and the master researcher. Thus, the obtained scientific results will allow to increase the effectiveness of intellectual activity in the fields: science, culture and art, education, design. "Integrative processes in culture express profound changes in the position of the individual in the modern world and the needs for its formation, development and self-realization. ${ }^{12}$

Developed innovative approaches will help to improve the quality of graduates of the master's degree in creative direction who will be highly educated, competent, enterprising, confident, tolerant, capable of dialogue and cooperation.

\section{Acknowledgements}

None.

\section{Conflict of interest}

The author declares no conflict of interest.

\section{References}

1. Portnov TV. Methodology of scientific research in choreography. Analysis of choreographic works, "Author's concept, form, genre, vocabulary of the choreographic work", Costume and scenic decoration of dance; Philosophy of Dance M, 2016; "The iconography of the ballet" M, 2017; "Stylization and reconstruction of the choreographic heritage", M, 2017; "Design technologies in art and the staging work of the choreographer", M, 2017 and others. 2016.

2. Romanovsky E Ya. The art of puppet theater in the context of national culture. Russia: Mordovian State University; 2008. 143 p.

3. Mikhailova EN. Synergetic paradigm in the study of the development of the ballet genre. Russia: Bulletin of the Orenburg State University; 2007. p. 18-24.

4. Kondratenko Yu A. The language of stage dance: species specificity and morphology. Russia: Mordovia University Publishing House; 2009. 136

5. Mineralova IG. Analysis of the work of art: style and inner form: Textbook / Mineralova IG. Russia: Science, Flint; 2011. 256 p.

6. Solovieva NN. Fundamentals of preparation for scientific activity and design of its results. 2006:74.

7. Anisimov OS. Methodology: function, essence, formation. 2006:502.

8. Terentyeva NA. Classical ballet: the role and functions in the contemporary art culture (all-Russian and regional aspects). Dis Kemerovo State University of Culture and Arts. Chelyabinsk, Russia; 2014. $207 \mathrm{p}$.

9. Kokhanovsky VP. Philosophy and methodology of science. 2005:576.

10. Krayevsky VV. Methodology of scientific research. SPb, 2001. 148 p.

11. Mikheev VI. The procedure for obtaining and processing experimental data in psychological and pedagogical research. 1986:84.

12. Kapustina LB. The nature of integrative entities in modern culture. Abstract of the dis. Russian Academy of Public Administration under the President of the Russian Federation. Moscow, Russia; 1995. 24 p. 